\title{
Glucose Stimulated Proinsulin Biosynthesis
}

\section{Rates of Turn Off after Cessation of the Stimulus}

\author{
D. Kaelin, A. E. Renold, and G. W. G. Sharp \\ Institut de Biochimie Clinique, University of Geneva, Geneva, Switzerland
}

Summary. Proinsulin biosynthesis was stimulated progressively to a plateau level at $45 \mathrm{~min}$ by $5.5 \mathrm{mmol} / \mathrm{l}$ glucose. The rate of biosynthesis promptly decreased following cessation of either 15 or $60 \mathrm{~min}$ exposure to this concentration of glucose. Actinomycin $\mathrm{D}$ had no effect on the rate of decline. In contrast, exposure to $20 \mathrm{mmol} / 1$ glucose caused a prolonged increase in proinsulin biosynthesis which was still apparent at $75 \mathrm{~min}$. After removal of the stimulus there was an initial decrease in the rate of proinsulin biosynthesis followed by persistently elevated rates. When proinsulin biosynthesis was stimulated by $20 \mathrm{mmol} / 1$ glucose in the presence of actinomycin $D$, there was a rapid switch off of biosynthesis and no persistent effect. Thus, two controls for regulation of proinsulin biosynthesis can be characterised: a prompt, rapidly reversible stimulation in response to low or high glucose concentrations and a persistent stimulation in response to high glucose concentrations. These two effects may represent the translational and transcriptional effects of glucose respectively.

Key words: Proinsulin biosynthesis, rat islets of Langerhans, sepharose-coupled insulin antibody, glucose, actinomycin D.

Islets of Langerhans respond to increased glucose concentrations with an increase in the rate of insulin secretion and an increase in the rate of proinsulin biosynthesis (1-12). After sustained periods of glucose stimulation, the insulin content of the islets falls so that proinsulin biosynthesis fails to keep pace with the rate of insulin release. Thus after the stimulation of insulin secretion the $\beta$-cells are faced with a for- ward control mechanism in that proinsulin biosynthesis is stimulated in an attempt to make up for an anticipated loss of insulin from the cells. In addition there appears to be an effect to increase the rate of synthesis of mRNA [13-15]. This could conceivably lead to a more persistent increase in the rate of proinsulin biosynthesis after cessation of the glucose stimulus [16]. Thus far, little is known of the control of proinsulin biosynthesis, its forward control or the way it is turned on and off.

In the work presented here the major emphasis is on the rate at which proinsulin biosynthesis is turned off, after two different concentrations of glucose applied for either 15 or 60 minutes. An attempt was also made, by use of actinomycin $D$, to assess the importance of increased mRNA synthesis in the long-term control of $\beta$-cell insulin content.

\section{Material and Methods}

Islets of Langerhans were isolated by the collagenase digestion technique of Lacy and Kostianovsky [17] from the pancreases of Wistar derived rats [150-200 g] fed ad libitum. After isolation the islets were washed twice with Hank's solution containing $2.5 \mathrm{mmol} / 1$ glucose, gassed with $95 \% \mathrm{O}_{2}, 5 \% \mathrm{CO}_{2}$ at $\mathrm{pH} \mathrm{7.4}$. Then batches of 20 or 25 islets were distributed into siliconised vials. The Hank's solution was removed, under microscopic control, and replaced by $0.5 \mathrm{ml}$ of Krebs-Ringer bicarbonate solution (KRB) containing $5 \mathrm{~g} / 1$ bovine serum albumin $2.5 \mathrm{mmol} / \mathrm{l}$ glucose and a mixture of essential amino acids (Eagle-Hela) without leucine. The islets was kept under continuous gassing for $45 \mathrm{~min}$ in a Dubnoff metabolic shaking incubator at $37^{\circ} \mathrm{C}$. They were then exposed to either $2.5,5.5$ or $20 \mathrm{mmol} / \mathrm{l}$ glucose for periods of 15 to $75 \mathrm{~min}$. Incorporation of ${ }^{3} \mathrm{H}$ - 
leucine into proinsulin was measured for $15 \mathrm{~min}$ periods at different times after the start of incubations in the presence or absence of actinomycin D, $5 \mu \mathrm{g} / \mathrm{ml}$. To study the rate of turn off of proinsulin biosynthesis, batches of 20-25 islets were incubated in $\mathrm{KRB}$ with $2.5 \mathrm{mmol} / \mathrm{l}$ glucose prior to stimulation with 5.5 or $20 \mathrm{mmol} / 1$ glucose for 15 or $60 \mathrm{~min} .{ }^{3} \mathrm{H}$ leucine was included during the $15 \mathrm{~min}$ stimulus and during the last $15 \mathrm{~min}$ of the $60 \mathrm{~min}$ stimulus. This measures the extent of stimulation of proinsulin biosynthesis. Subsequent measurements of proinsulin biosynthesis were made by including ${ }^{3} \mathrm{H}$-leucine during each $15 \mathrm{~min}$ of the hour following the end of glucose stimulation, when the islets were returned to $\mathrm{KRB}$ with $2.5 \mathrm{mmol} / \mathrm{l}$ glucose. Incorporation was performed in the presence of $100 \mu \mathrm{Ci} \mathrm{L}-4,5-{ }^{3} \mathrm{H}-$ leucine (The Radiochemical Centre, Amersham, Bucks, U. K.). It has been shown previously that in 15 minutes, ${ }^{3} \mathrm{H}$-leucine is incorporated into proinsulin but not into insulin so that there is no loss of radioactivity into the medium [11].

At the end of the incorporation period the islets were washed twice with ice-cold KRB solution and $2 \mathrm{ml}$ of glycine buffer $0.2 \mathrm{~mol} / 1$ (pH 8.8) plus $2.5 \mathrm{~g} / 1$ human serum albumin. The islets were sonicated for 40 seconds (Branson Sonic Power Company, Danbury, Conn., U. S. A.) and the mixture centrifuged at $4000 \times \mathrm{g}$ for 30 minutes. This procedure gives identical recovery to acid-ethanol extraction according to the method of Davoren [18] as shown previously [10, 11]. A $0.5 \mathrm{ml}$ aliquot of the supernatant was then placed on $0.9 \times 2.0 \mathrm{~cm}$ columns of $\mathrm{CNBr}$-activated Sepharose 4B (Pharmacia, Uppsala, Sweden) covalently linked to anti-insulin antibodies $[12,19-21]$ and equilibrated with $0.2 \mathrm{~mol} / \mathrm{l}$ glycine buffer $2.5 \mathrm{~g} / \mathrm{l}$ HSA pH 8.8. The antibodies were purified prior to the linking reaction by ammonium sulphate precipitation from guinea-pig anti-porcine insulin antiserum kindly provided by Dr.P.H. Wright, Indianapolis, Ind. The samples were left on the columns overnight at $4^{\circ} \mathrm{C}$ and the radioactivity not incorporated into immunoreactive proteins washed away with $20 \mathrm{ml}$ of glycine buffer. Radioactivity incorporated into proinsulin was eluted with $5 \mathrm{ml}$ of $1 \mathrm{~mol} / \mathrm{l}$ acetic acid containing $2.5 \mathrm{~g} / \mathrm{l}$ of bovine serum albumin. For measurement of ${ }^{3} \mathrm{H}$-leucine incorporation in proinsulin a $1 \mathrm{ml}$ aliquot of the acetic acid eluate was mixed with $6 \mathrm{ml}$ of Instagel in plastic vials and assayed by scintillation spectrometry.

The total binding capacity of different batches of the affinity columns was never less than $20 \mu \mathrm{g}$ insulin per column and in the experiments only 0.2 to $0.3 \mu \mathrm{g}$ insulin was applied. Furthermore, when $1 \mu \mathrm{g}$ insulin samples were applied in $0.5 \mathrm{ml}$ portions, $96 \%$ retention of the insulin was achieved. Recovery of this insulin after elution by $5 \mathrm{ml}$ acetic acid was essentially complete. The affinity of the antibodies used for pork proinsulin was $65 \%$ of that for rat insulin (rat proinsulin affinity is not known). Specificity of the affinity binding was assessed by the addition of ${ }^{125} \mathrm{I}$-albumin, ${ }^{125} \mathrm{I}$-glucagon and ${ }^{3} \mathrm{H}$-leucine to the anti-insulin antibody columns. $100 \%$ of these materials was eluted with the glycine buffer and none with the acetic acid. Control columns prepared with the ammonium sulphate precipitated fraction from normal guinea-pig serum were also tested with ${ }^{125}$ I-insulin. ( $\mathrm{Na}^{125} \mathrm{I}$ used to prepare the labelled compounds was from Eidg. Institut für Reaktorforschung, Würenlingen)-Again, $100 \%$ elution with glycine buffer was achieved.

Statistical data were obtained by paired analysis using Student's t-test.

\section{Results}

\section{The Onset of Stimulation of Proinsulin Biosynthesis (Fig. 1)}

Isolated islets were incubated in $2.5 \mathrm{mmol} / 1$ glucose for 45 minutes before measurement of ${ }^{3} \mathrm{H}$-leucine incorporation into proinsulin in a medium glucose concentration of $2.5,5.5$ or $20 \mathrm{mmol} / \mathrm{l} .{ }^{3} \mathrm{H}$-leucine incorporation was determined in each of five 15 minute periods between 0 and 75 minutes following the 45 minute equilibration period. Under control conditions, $2.5 \mathrm{mmol} / \mathrm{l}$ glucose throughout, no change in the rate of ${ }^{3} \mathrm{H}$-leucine incorporation into proinsulin occurred from 0-75 minutes. When the glucose concentration was changed to $5.5 \mathrm{mmol} / \mathrm{l}$ glucose ${ }^{3} \mathrm{H}$-leucine incorporation increased progressively up to between 45 and 60 minutes, and then remained constant. With change to $20 \mathrm{mmol} / \mathrm{l}$ glucose, proinsulin biosynthesis was again progressively increased with time and appeared to be still increasing from 45 to 75 minutes.

\section{The Rates of Proinsulin Biosynthesis after Cessation of a Glucose Stimulus}

For these studies two concentrations of glucose (5.5 and $20 \mathrm{mmol} / \mathrm{l}$ ) were employed and the effects of brief stimulation, 15 minutes, and a long stimulation, 60 minutes, were examined. The rates of proinsulin biosynthesis after 15 and 60 minutes of stimulation by $5.5 \mathrm{mmol} / 1$ glucose are shown in Figure 2 . With the short stimulus, $5.5 \mathrm{mmol} / 1$ glucose stimulated proinsulin biosynthesis by $66 \%$. Because of this mild stimulation the rate at which the stimulated biosynthesis was turned off cannot be described precisely. 

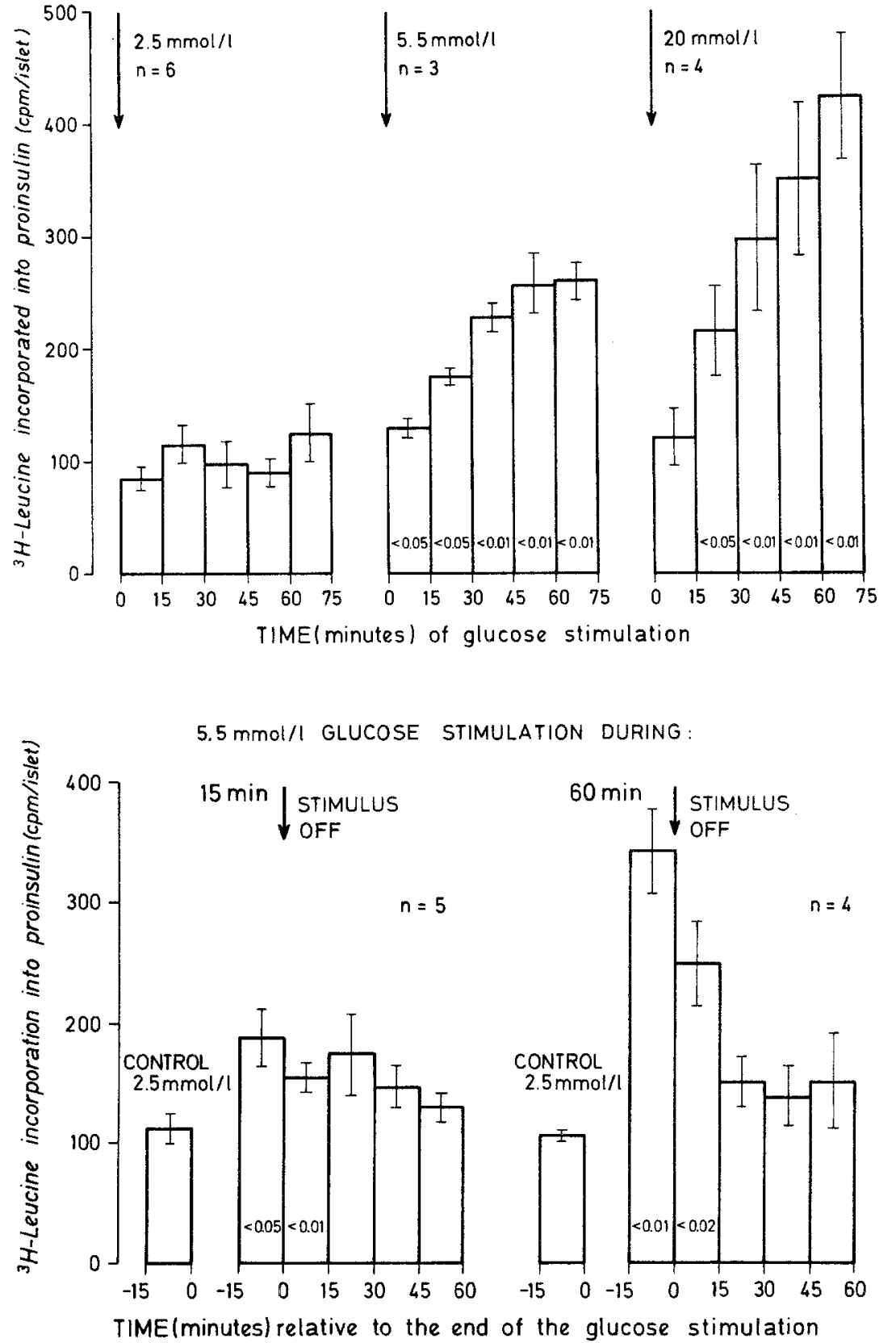

Fig. 1. Time course of the increase in the rate of proinsulin biosynthesis following stimulation by 5.5 and $20 \mathrm{mmol} / \mathrm{l}$ glucose. Vertical lines represent \pm SEM. P values for all significant differences from the appropriate control $(2.5 \mathrm{mmol} / \mathrm{l})$ measurements are shown
Fig. 2. Time course of the decrease of proinsulin biosynthesis following stimulation by $5.5 \mathrm{mmol} / \mathrm{lglucose}$ for periods of 15 and $60 \mathrm{~min}$
However, the rate decreased such that at 45-60 minutes after removal of the glucose stimulus, proinsulin biosynthesis was not significantly different from non-stimulated rates. With the 60 minute stimulus, $5.5 \mathrm{mmol} / 1$ glucose increased proinsulin biosynthesis by $220 \%$ relative to control. When the glucose stimulus was removed the rate of biosynthesis declined rapidly so that at $15-30$ minutes the rate was only $40 \%$ above, and not significantly different from, the control value. The rapid dissolution of elevated rates of proinsulin biosynthesis after $5.5 \mathrm{mmol} / 1$ glucose were in contrast to the results obtained after stimulation with $20 \mathrm{mmol} / \mathrm{l}$ glucose. These results are shown in Figure 3 . A 15 minute stimulation by $20 \mathrm{mmol} / 1$ glucose raised proinsulin biosynthesis by more than $80 \%$. Following removal of the glucose little decline in proinsulin biosynthesis occurred so that after 60 minutes the rate was significantly raised by $60 \%$. This failure to turn off rapidly after stimulation by $20 \mathrm{mmol} / 1$ glucose is seen clearly in the results of the 60 minute experiments. Proinsulin biosynthesis was stimulated by $260 \%$. The rate declined in the first 15 minutes after removal but the rate of decline then slowed so that after 60 minutes 

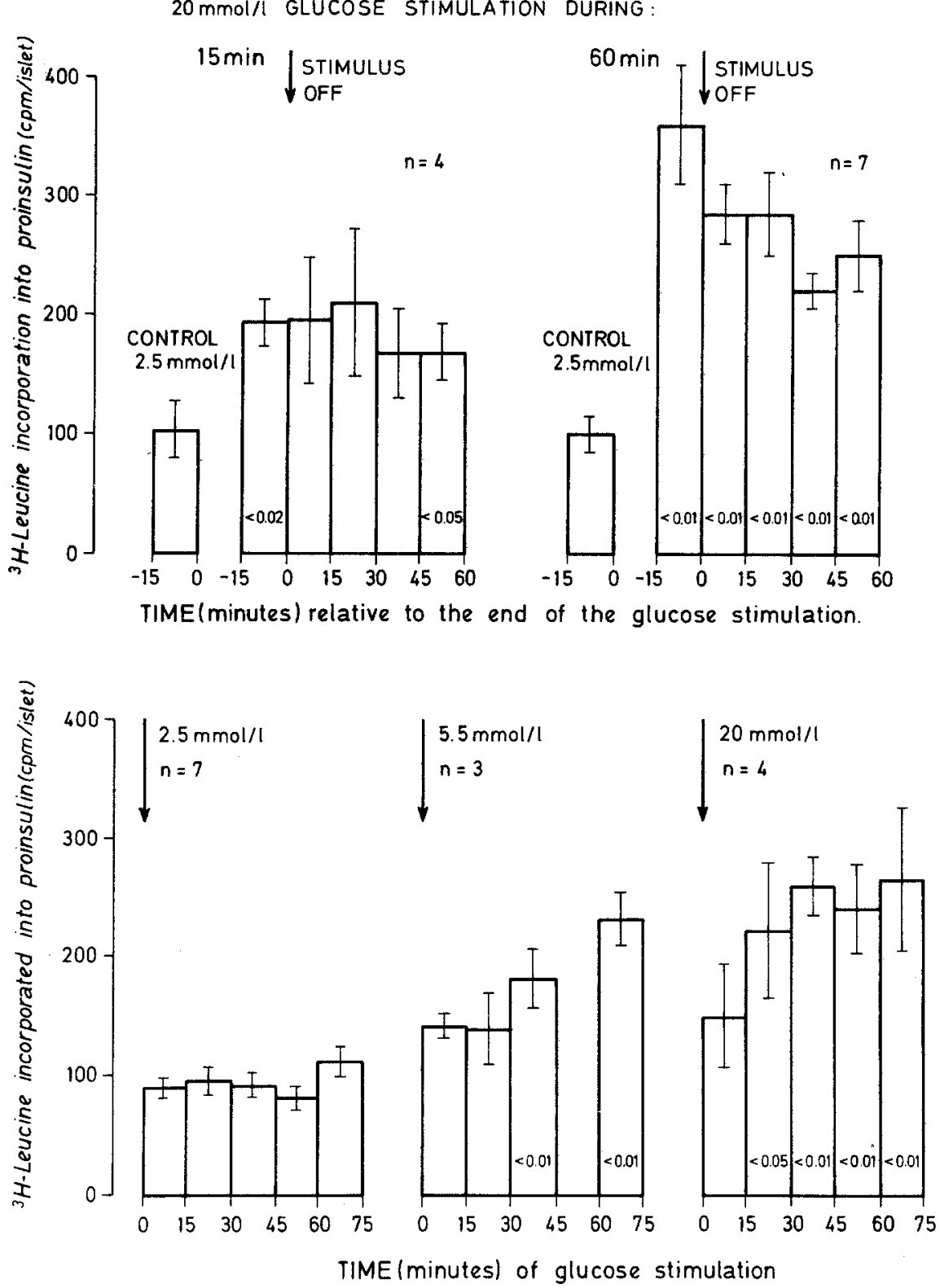

Fig. 3. Time course of the decrease of proinsulin biosynthesis following stimulation by $20 \mathrm{mmol} / 1$ glucose for periods of 15 and $60 \mathrm{~min}$
Fig. 4. Time course of the increase in the rate of proinsulin biosynthesis following stimulation by 5.5 and $20 \mathrm{mmol} / 1$ glucose in the presence of actinomycin $\mathrm{D}(5 \mu \mathrm{g} / \mathrm{ml})$ the rate of biosynthesis was still significantly raised by $150 \%$. Again, it is clear that $20 \mathrm{mmol} / 1$ glucose caused a persistent stimulatory effect upon proinsulin biosynthesis. In contrast short or long stimulation with $5.5 \mathrm{mmol} / 1$ glucose had only a transient effect on biosynthesis.

\section{The Effects of Actinomycin D on the Onset of Proinsulin Biosynthesis}

In order to define glucose control of proinsulin biosynthesis by an immediate rapid effect and by a longer term effect, probably via induction of messenger RNA, the studies were repeated in the presence of actinomycin D $(5 \mu \mathrm{g} / \mathrm{ml})$.
In Figure 4 it can be seen that with $2.5 \mathrm{mmol} / \mathrm{l}$ glucose in the presence of actinomycin $\mathrm{D}$, proinsulin biosynthesis remained constant from $0-75$ minutes. Comparison with Figure 1 shows that actinomycin D had no effect upon the rate of proinsulin biosynthesis. Similarly, actinomycin D had no effect upon the progressive stimulation of biosynthesis by $5.5 \mathrm{mmol} / 1$ glucose. When $20 \mathrm{mmol} / 1$ glucose was studied, however, a late effect of actinomycin D was detected. Proinsulin biosynthesis was stimulated, as expected, to 45 minutes but thereon no further stimulation was seen. Comparison with Figure 1 shows that the stimulation of proinsulin synthesis by $20 \mathrm{mmol} / \mathrm{l}$ glucose beyond 45 minutes was blocked. 


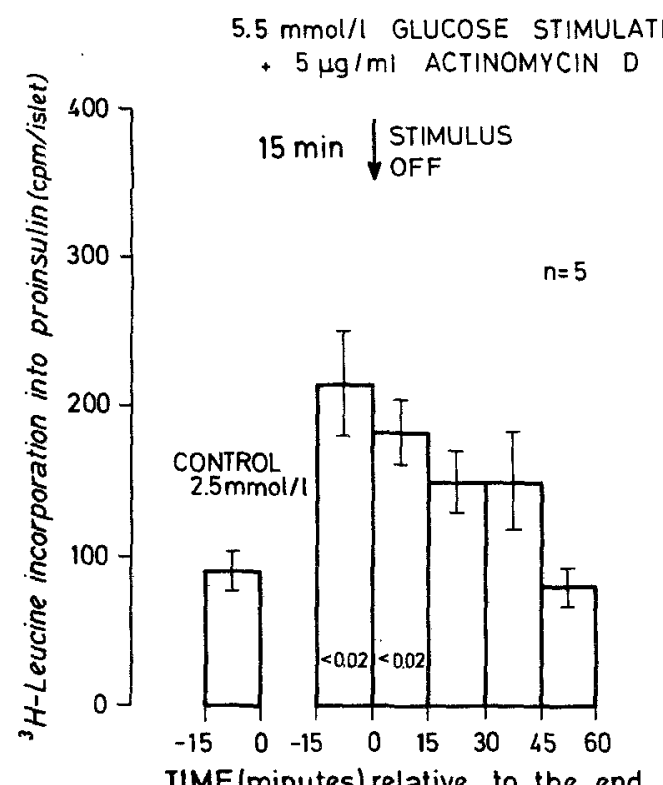

TIME(minutes) relative to the end

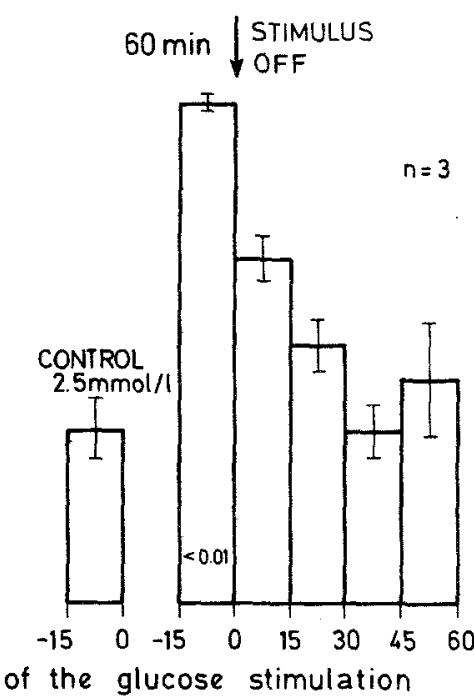

DURING :

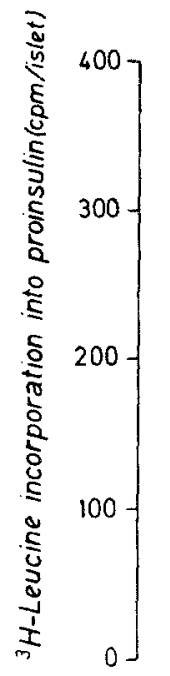

$20 \mathrm{mmol} / 1$ GLUCOSE STIMULATION

+ $5 \mu \mathrm{g} / \mathrm{ml}$ ACTINOMYCIN D

$\left.15 \min \right|_{\text {OFF }} ^{\text {STIMULUS }}$

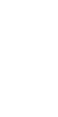

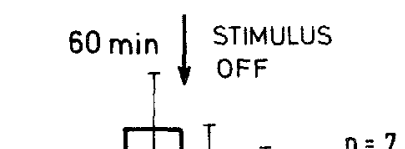

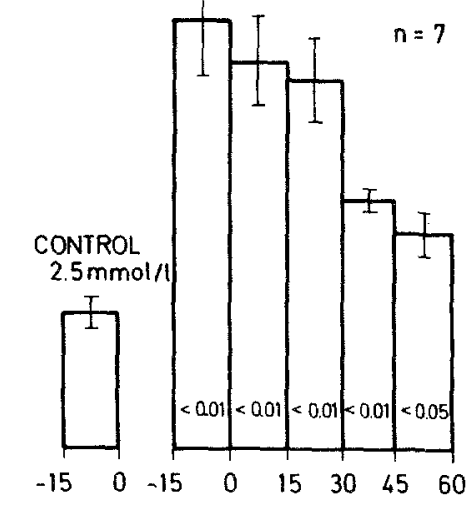

TIME (minutes) relative to the end of the glucose stimulation
Fig. 5. Time course of the decrease of proinsulin biosynthesis following stimulation by $5.5 \mathrm{mmol} / \mathrm{l}$ glucose for periods of 15 and $60 \mathrm{~min}$ in the presence of actinomycin D $(5 \mu \mathrm{g} / \mathrm{ml})$
Fig. 6. Time course of the decrease of proinsulin biosynthesis following stimulation by $20 \mathrm{mmol} / \mathrm{l}$ glucose for periods of 15 and $60 \mathrm{~min}$ in the presence of actinomycin D $(5 \mu \mathrm{g} / \mathrm{ml})$
4. The Rates of Proinsulin Biosynthesis after Cessation of a Glucose Stimulus Applied in the Presence of Actinomycin D

After a $15 \mathrm{~min}$ stimulus with $5.5 \mathrm{mmol} / \mathrm{l}$ glucose, the stimulated rate of proinsulin biosynthesis returned to basal levels at 45-60 min (Fig. 5). Similar results were obtained when the effects of actinomycin D on the rates of proinsulin biosynthesis following stimulation with $5.5 \mathrm{mmol} / \mathrm{l}$ glucose for $60 \mathrm{~min}$ were studied. Again, the marked stimulation of proinsulin biosynthesis rapidly returned to basal values as they had in the absence of actinomycin D.

When $20 \mathrm{mmol} / 1$ glucose was the stimulus for increased synthesis, effects of actinomycin D were apparent (Fig. 6). With the 15 minute stimulus in the presence of actinomycin $\mathrm{D}$, proinsulin biosynthesis had returned to basal values at 45-60 min. This is in contrast to the persistence of stimulated biosynthesis seen in the absence of the inhibitor (see Fig. 3).

A similar lack of persistence of the stimulatory effect of $20 \mathrm{mmol} / \mathrm{l}$ glucose in the presence of actinomycin $D$ was seen even when the glucose exposure was for $60 \mathrm{~min}$ (Fig. 6). At 45-60 min after cessation of the glucose stimulus, proinsulin biosynthesis was significantly lower than in the absence of actinomycin $\mathrm{D}$. At this time the rate of biosynthesis was only $58 \%$ above control compared with $150 \%$ above in the absence of actinomycin $D$. 


\section{Discussion}

Proinsulin biosynthesis in islets of Langerhans occurs at a rate which is slower than the rate at which insulin can be released when the islets are stimulated. Thus to ensure adequate supplies of insulin for release, the islet relies on a biosynthetic process which is continually active. This is reflected in a left shift in the glucose dose response relationship for stimulation of biosynthesis relative to release $[8,12]$, and in a persistence of stimulated proinsulin biosynthesis after cessation of the stimulus [16]. By these means the islets have a reserve of insulin to cope with sustained stimulation of release. The precise mechanisms regulating insulin content are unknown and a feed-back control of biosynthesis by the insulin content appears not to be a dominant mechanism [12]. Rather, the stimuli for insulin release promptly stimulate proinsulin biosynthesis at a time when the insulin content is not significantly changed. This lack of feed-back control by insulin content is seen particularly in experiments performed in the absence of calcium in the medium. Under these conditions, glucose can stimulate proinsulin biosynthesis in the absence of an effect on insulin release and therefore without decrease of insulin content [22].

To investigate how proinsulin biosynthesis is regulated in response to glucose stimulation of different intensity and duration, and particularly with regard to the persisting increased rates of biosynthesis after the end of glucose stimulation, a study both of onset and offset of proinsulin biosynthesis was performed. It can be concluded from the results that with a change from $2.5 \mathrm{mmol} / 1$ glucose to either 5.5 or $20 \mathrm{mmol} / \mathrm{l}$ a prompt stimulation of proinsulin biosynthesis occurs which is similar up to $30 \mathrm{~min}$ for both concentrations of glucose. Beyond $30 \mathrm{~min}$, however, there was a difference. With $5.5 \mathrm{mmol} / \mathrm{l}$ glucose present the rate of proinsulin biosynthesis levelled off whereas with $20 \mathrm{mmol} / \mathrm{l}$ glucose the rate continued to increase. As this continued increase in the rate of proinsulin synthesis was blocked by actinomycin $D$ it is likely that the initial increase in rate after change to high glucose is a post-transcriptional effect on the biosynthetic process while the continued increase beyond $30 \mathrm{~min}$ is a transcriptional effect. This presumed increase in the amount of mRNA for proinsulin biosynthesis, which appears some 30-45 min after exposure to high glucose, was first described by Permutt and Kipnis [15].

From the results on the rate at which stimulated proinsulin biosynthesis was turned off, it can be concluded that the post-transcriptional effect on biosynthesis, which results in prompt stimulation, is equally promptly turned off. In contrast, the transcriptional effect results in a persistent stimulation of proinsulin biosynthesis. For example, with $5.5 \mathrm{mmol} / 1$ glucose as the stimulus, whether applied for 15 or $60 \mathrm{~min}$, stimulated proinsulin biosynthesis rapidly returned to normal rates when the glucose stimulus was stopped. This is particularly well seen in Figure 2 after $60 \mathrm{~min}$ exposure. Comparison with Figure 3 reveals that whether high glucose exposure was for 15 or $60 \mathrm{~min}$ the stimulated rate of proinsulin biosynthesis was maintained and still significantly elevated $60 \mathrm{~min}$ after cessation of the stimulus. Furthermore, it can be seen in Figure 3 that the two components of the stimulatory process (transcriptional and post-transcriptional) can be detected from the rates of decline of stimulated biosynthesis when $20 \mathrm{mmol} / 1$ glucose is replaced with $2.5 \mathrm{mmol} / \mathrm{l}$. Thus, there is a rapid initial fall, presumably due to the switching off of the post-transcriptional effect, followed by a stable plateau of still elevated biosynthesis presumably due to the increased amounts of mRNA as a result of increased transcription. That this conclusion seems likely is shown by the fact that in the presence of actinomycin D, $20 \mathrm{mmol} / \mathrm{l}$ glucose stimulated biosynthesis promptly and that this stimulation was rapidly abolished after reduction of the glucose concentration to $2.5 \mathrm{mmol} / \mathrm{l}$.

In conclusion, it appears that the $\beta$-cells of islets of Langerhans react to high glucose concentrations and anticipated high rates of insulin release by transcriptional and post-transcriptional effects to stimulate proinsulin biosynthesis. $20 \mathrm{mmol} / 1$ glucose, but not $5.5 \mathrm{mmol} / 1$ glucose, will elicit these two effects. Small increases in glucose concentration as tested here by changing from $2.5 \mathrm{mmol} / 1$ to $5.5 \mathrm{mmol} / \mathrm{lglu}$ cose cause only the post-transcriptional stimulatory effect on biosynthesis. The post-transcriptional effect is rapid in onset and rapidly dissipated after removal of the glucose stimulus. The transcriptional effect to increase the mRNA content of the $\beta$-cells has an onset time some $30 \mathrm{~min}$ after exposure to high glucose and results in a persistent elevation of proinsulin biosynthesis. The full duration of this persistent effect was not determined in this study. This system of forward control of $\beta$-cell insulin content appears to be primarily dependent upon the glucose concentration. For example, high $(20 \mathrm{mmol} / \mathrm{l})$ glucose for only $15 \mathrm{~min}$ resulted in a persistent elevation of the rate of proinsulin biosynthesis whereas $5.5 \mathrm{mmol} / 1$ glucose for $60 \mathrm{~min}$ did not. The effect of duration of exposure to high glucose concentration, after maximum rates of biosynthesis have been achieved, on the duration of elevated proinsulin biosynthesis remains to be examined.

Acknowledgements. These studies were supported by the Swiss National Science Foundation (grants nos 3.1060.73 and 3.774.076). 


\section{References}

1. Howell, S. L., Taylor, K. W.: Effects of glucose concentration on incorporation of ${ }^{3} \mathrm{H}$-leucine into insulin using isolated mammalian islets of Langerhans. Biochim. Biophys. Acta 130, 519-521 (1966)

2. Steiner, D. F., Cunningham, D. D., Spigelman, L., Aten, B.: Insulin biosynthesis: evidence for a precursor. Science 157, 697-700 (1967)

3. Lin, B. J., Haist, R. E.: Insulin biosynthesis: effects of carbohydrates and related compounds. Can. J. Physiol. Pharmacol. 47, 791-801 (1969)

4. Clark, J.L., Steiner, D.F.: Insulin biosynthesis in the rat: demonstration of two proinsulins. Proc. Natl. Acad. Sci. U. S. A. 62, 278-285 (1969)

5. Morris, G.E., Korner, A.: The effect of glucose on insulin biosynthesis by isolated islets of Langerhans in the rat. Biochim. Biophys. Acta 208, 404-413 (1970)

6. Tanese, T., Lazarus, N. R., Devrim, S., Recant, L.: Synthesis and release of proinsulin and insulin by isolated rat islets of Langerhans. J. Clin. Invest. 49, 1394-1404 (1970)

7. Lin, B. J., Nagy, B. R., Haist, R. E.: Effect of various concentrations of glucose on insulin biosynthesis. Endocrinology 91 , 309-311 (1972)

8. Pipeleers, D. G., Marichal, M., Malaisse, W. J.: The stimulussecretion coupling of glucose induced insulin release XIV. Glucose regulation of insular biosynthetic activity. Endocrinology 93, 1001-1011 (1973)

9. Schatz, J., Maier, V., Hinz, M., Nierle, C., Pfeiffer, E.F.: Stimulation of ${ }^{3} \mathrm{H}$-leucine incorporation into the proinsulin and insulin fraction of isolated pancreatic mouse islets in the presence of glucagon, theophylline and cyclic AMP. Diabetes 22, 433-441 (1973)

10. Trueheart, P.A., Maldonato, A., Kaelin, D., Renold, A.E., Sharp, G. W. G.: Proinsulin synthesis in islets of Langerhans from Spiny mice (Acomys Cahirinus). Diabetologia 12, 463-470 (1976)

11. Maldonato, A., Trueheart, P.A., Renold, A.E., Sharp, G.W.G.: Effects of streptozotocin in vitro on proinsulin biosynthesis, insulin release and ATP content of isolated rat islets of Langerhans. Diabetologia 12, 471-481 (1976)

12. Maldonato, A., Renold, A. E., Sharp, G.W.G., Cerasi, E.: Glucose-induced proinsulin biosynthesis: role of cyclic AMP. Diabetes 26, 538-545 (1977)

13. Jarrett, R.J., Keen, H., Track, N.S.: Glucose and RNA syn- thesis in mammalian islets of Langerhans. Nature 213, 634-635 (1967)

14. Jarrett, R. J., Track, N.S., Keen, H.: Ribonucleic acid metabolism and insulin synthesis. In: S. Falkmer, B. Hellman, I. B. Taljedal (Eds.): Structure and metabolism of the pancreatic islets. Wenner-Gren Center Int. Symp. Ser. 16, 371-379. New York: Pergamon Press 1970

15. Permutt, M. A., Kipnis, D. M.: Insulin biosynthesis. I. On the mechanism of glucose stimulation. J. Biol. Chem. 247, 1194-1199 (1972)

16. Zucker, P., Logothetopoulos, J.: Persisting enhanced proinsulin-insulin and protein biosynthesis ( ${ }^{3} \mathrm{H}$-leucine incorporation) by pancreatic islets of the rat after glucose exposure. Diabetes 24, 194-200 (1975)

17. Lacy, P.E., Kostianovsky, M.: Method for the isolation of intact islets of Langerhans from the rat pancreas. Diabetes 16, 35-39 (1967)

18. Davoren, P. R.: The isolation of insulin from a single cat pancreas. Biochim. Biophys. Acta 63, 150-153 (1962)

19. Akunuma, Y., Kuzuya, T., Hazashi, M., Ide, T., Kuzuya, N.: Immunological reactivity of insulin to Sepharose coupled with insulin antibody: its use for the extraction of insulin from serum. Biochem. Biophys. Res. Commun. 38, 947-953 (1970)

20. Berne, C.: Anti-insulin serum coupled to Sepharose $4 \mathrm{~B}$ as a tool for the investigation of insulin biosynthesis in the B-cells of obese hyperglycemic mice. Endocrinology 97, 1241-1247 (1975)

21. Bone, A. J., Taylor, K. W.: Metabolic adaptation to pregnancy shown by increased biosynthesis of insulin in islets of Langerhans isolated from pregnant rats. Nature 262, 501-502 (1976)

22. Pipeleers, D.G., Marichal, M., Malaisse, W.J.: The stimulussecretion coupling of glucose-induced insulin release. XV. Participation of cations in the recognition of glucose by the $\beta$-cell. Endocrinology 93, 1012-1018 (1973)

Received: November 7, 1977,

and in revised form: January 12, 1978

D. Kaelin

Institut de Biochimie Clinique

Sentier de la Roseraie

CH-1211 Geneva 4

Switzerland 